\section{(6) OPEN ACCESS}

\title{
Net clinical benefit of warfarin in individuals with atrial fibrillation across stroke risk and across primary and secondary care
}

\author{
Victoria Allan, Amitava Banerjee, Anoop Dinesh Shah, Riyaz Patel, Spiros Denaxas, \\ Juan-Pablo Casas, Harry Hemingway
}

\begin{abstract}
- Additional material is published online only. To view please visit the journal online (http://dx.doi.org/10.1136/ heartjnl-2016-309910).

Farr Institute of Health Informatics Research, Institute of Health Informatics, University College London, London, UK
\end{abstract}

\section{Correspondence to} Professor Harry Hemingway, Farr Institute of Health Informatics Research, University College London, 222 Euston Road, London NW1 2AD, UK; h.hemingway@ucl.ac.uk

Received 29 April 2016 Revised 21 July 2016 Accepted 30 July 2016 Published Online First 31 August 2016

\section{SLinked}

- http://dx.doi.org/10.1136/ heartjnl-2016-310325

\section{CrossMark}

To cite: Allan $\mathrm{V}$ Banerjee $A$, Shah $A D$, et al. Heart 2017;103:210-218.

\section{ABSTRACT}

Objective To investigate net clinical benefit (NCB) of warfarin in individuals with atrial fibrillation (AF) across stroke risk and across primary and secondary care. Methods We conducted a linked electronic health record cohort study of 70206 individuals with initial record of diagnosis of AF in primary $(n=29568)$ or secondary care $(n=40638)$ in England (1998-2010). We defined stroke risk according to the $\mathrm{CHA}_{2} \mathrm{DS}_{2}$-VASC score, and followed individuals over a median 2.2 years for 7005 ischaemic strokes (IS) and for 906 haemorrhagic strokes (HS). We calculated incidence rates (IRs) and 95\% Cls per 100 person-years (PYs) (IR (95\% CI)/100 PY) of IS and HS, with and without use of warfarin, and the NCB (ie, number of IS avoided) per 100 PYs of warfarin use (NCB (95\% CI)/100 PY).

Results Compared with individuals with initial record of diagnosis in secondary care, those in primary care had lower scores of IS risk $\left(\mathrm{CHA}_{2} \mathrm{DS}_{2}\right.$-VASc $\leq 2: 30.8 \%$ vs $20.6 \%)$, and lower overall incidence of IS (IR (95\% CI)/ 100 PY: 2.3 (2.2 to 2.4 ) vs 4.3 (4.2 to 4.4 ), $p$ value $=0.00)$; however among individuals with $\mathrm{CHA}_{2} \mathrm{DS}_{2}-\mathrm{VAS} \mathrm{C}=0,1$ or 2 there were no differences in IS rate between those with initial record of diagnosis in primary care or secondary care (IR (95\% CI)/100 PY: 0.2 (0.1 to 0.3$)$ vs $0.3(0.2$ to 0.5$)$, p value $=0.16)$, $(I R$ (95\% CI)/100 PY: $0.6(0.4$ to 0.7$)$ vs $0.7(0.6$ to 0.9$)$, $p$ value $=0.08)$ and $(\mathrm{IR}(95 \% \mathrm{CI}) / 100 \mathrm{PY}: 1.1$ (1.00 to 1.3$)$ vs 1.4 (1.2 to 1.6), $p$ value $=0.05)$, respectively. For $\mathrm{CHA}_{2} \mathrm{DS}_{2}$-VASc $=0,1$ and 2, IRs of IS with versus without warfarin were (IR (95\% CI)/100 PY: $0.4(0.2$ to $0.8)$ vs 0.2 (0.1 to 0.3$)$, p value $=0.16)$, $(\mathrm{IR}(95 \% \mathrm{CI})$ / 100 PY: 0.4 (0.3 to 0.7 ) vs 0.7 (0.6 to 0.8$)$, $\mathrm{p}$ value $=0.03)$ and (IR (95\% CI)/100 PY: 0.8 (0.7 to $1.0)$ vs 1.4 (1.3 to 1.6$)$, $p$ value $=0.00)$, respectively. We found a significant positive NCB of warfarin from $\mathrm{CHA}_{2} \mathrm{DS}_{2}-\mathrm{VASC} \geq 2$ in men (NCB $(95 \% \mathrm{Cl}) / 100 \mathrm{PY}: 0.5$ (0.1 to 0.9$)$ ) and from $\mathrm{CHA}_{2} \mathrm{DS}_{2}-\mathrm{VAS} \mathrm{C} \geq 3$ in women (NCB (95\% CI)/100 PY: 1.5 (1.1 to 1.9)).

Conclusions $\mathrm{CHA}_{2} \mathrm{DS}_{2}$-VASC accurately stratifies IS risk in individuals with AF across both primary and secondary care. However, the incidence rate of ischaemic stroke at $\mathrm{CHA}_{2} \mathrm{DS}_{2}-\mathrm{VASC}=1$ are lower than previously reported, which may change the decision to start anticoagulation with warfarin in these individuals.

\section{INTRODUCTION}

$\mathrm{CHA}_{2} \mathrm{DS}_{2}$-VASc (congestive heart failure, hypertension, age $\geq 75$ years, diabetes mellitus, history of stroke or thromboembolism, vascular disease, age $65-74$ years and female sex) is the most widely used and validated clinical prediction score for assessment of ischaemic stroke (IS) risk in individuals with atrial fibrillation (AF). The score ranges from 0 to 9 , and assigns 1 or 2 points for each stroke risk factor. ${ }^{1} \mathrm{CHA}_{2} \mathrm{DS}_{2}$-VASc aims to identify individuals with the lowest stroke risk $\left(\mathrm{CHA}_{2} \mathrm{DS}_{2}-\mathrm{VASc}=0\right)$ in whom prevention with anticoagulants is not advised. The advice for individuals with one stroke risk factor $\left(\mathrm{CHA}_{2} \mathrm{DS}_{2}-\mathrm{VAS} \mathrm{c}=1\right)$ varies in current clinical practice guidelines, as it remains uncertain whether the benefits of anticoagulants outweigh the harms. ${ }^{2} 34$

A recent systematic review of incidence rates (IRs) of IS in individuals with $\mathrm{CHA}_{2} \mathrm{DS}_{2}$-VASc $=1$ reported highly heterogeneous annualised rates ranging from $0.1 \%$ to $6.6 \%$ across studies, with wide uncertainty $(0-3.23 \%)$ in the pooled estimate of $1.6 \% .^{5}$ Among the 10 included studies, there were 0 studies that involved individuals across both primary and secondary care. Primary care accounts for over $40 \%$ of initial AF diagnoses. ${ }^{6}$ Therefore without the inclusion of these individuals, it is unclear whether previously reported stroke rates are representative of the full patient pathway. Furthermore, in many countries (including the UK, Denmark and Sweden) clinical information coded and recorded electronically in secondary care is not integrated with that of primary care. Thus, without the inclusion of risk factors diagnosed in primary care, previous studies based on secondary care data may have inaccurately calculated individuals' $\mathrm{CHA}_{2} \mathrm{DS}_{2}$-VASc scores (figure 1). ${ }^{8}$ Lastly, without conducting net clinical benefit (NCB) analyses, which weigh up benefits and harms of anticoagulants, the review was limited in the extent to which it could inform recommendations for clinical practice guidelines.

We therefore implemented the $\mathrm{CHA}_{2} \mathrm{DS}_{2}$-VASc score in a large, nationally representative linked electronic health record (EHR) study of 70206 individuals with initial record of diagnosis of nonvalvular AF in primary or secondary care in England in 1998-2010. We selected an observation period prior to the introduction of direct oral anticoagulants (DOACs), in order to more accurately study outcomes with warfarin. Our objectives were (1) to investigate incidence of IS in individuals with AF across stroke risk and across primary and secondary care, and (2) to consider benefits and harms of warfarin in NCB analyses. 
Actual patient pathway integrating information from primary care (green) and secondary care (blue):

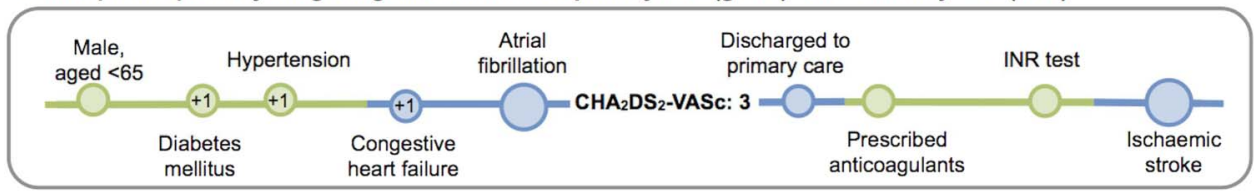

Information recorded in primary care:

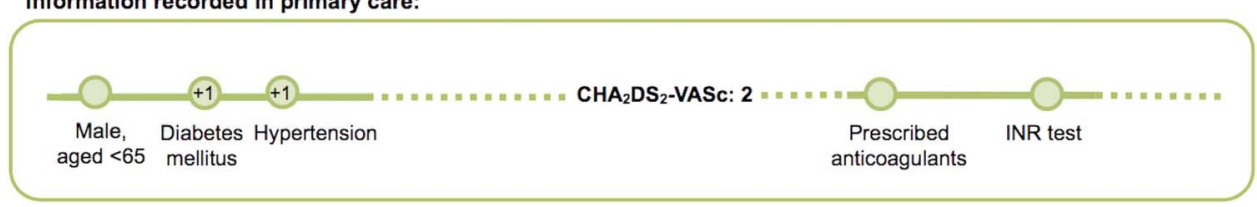

Information recorded in secondary care:

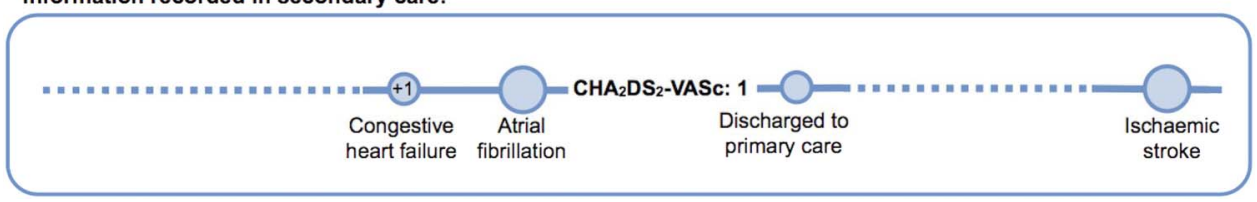

Figure 1 Example of one patient's actual pathway and how information is captured in primary care and secondary care records. This illustrates how lack of integration of primary and secondary care information may lead to underestimation of $\mathrm{CHA}_{2} \mathrm{DS}_{2}-\mathrm{VASC}$ scores. Patient interactions occurring in primary and secondary care are colour-coded green and blue, respectively. +1 indicates scoring of one $\mathrm{CHA}_{2} \mathrm{DS}_{2}$-VASc risk factor point. As shown, this patient has CHA2DS2-VASC $=1$ based on secondary care records only, CHA2DS2-VASc $=2$ based on primary care records only, but is truly CHA2DS2-VASC=3 based on integrated primary and secondary care records. INR, International Normalised Ratio.

\section{METHODS}

\section{Data sources}

We used available data from the population-based CALIBER (ClinicAl research using LInked Bespoke studies and EHRs) study. ${ }^{7}$ CALIBER connects four national sources of EHRs in England, including a subset of primary care data from the Clinical Practice Research Datalink GP OnLine Database (CPRD GOLD), ${ }^{9}$ secondary care data from Hospital Episode Statistics (HES),${ }^{10}$ data on admissions to hospital with an acute coronary syndrome from the Myocardial Ischaemic National Audit Project $^{11}$ and cause-specific mortality data from the Office of National Statistics (ONS). ${ }^{12}$ The denominator population comprises individuals captured in CPRD GOLD, who are representative of the UK population in terms of gender, age, ethnicity ${ }^{13}$ and overall mortality. ${ }^{14}$ For this analysis we used CPRD GOLD, HES and ONS. CPRD GOLD is coded using Read clinical terms, ${ }^{15}$ and HES and ONS using the International Classification of Diseases V.10 (ICD-10). ${ }^{16}$ A key objective of CALIBER is to facilitate transparent and reproducible research of these data through the publication of disease phenotypes and tools to support statistical analysis, and these can be found freely available at caliberresearch.org. CALIBER research has been shown to replicate known and discover new associations with risk factors for the onset of disease. ${ }^{17-20}$

\section{Selection of individuals with non-valvular AF}

We used the previously reported CALIBER phenotype algorithm for AF to identify all individuals with a diagnosis in primary or secondary care between 1998 and 2010. ${ }^{6}$ The algorithm includes primary and secondary care (main and subsidiary) recorded diagnoses, and inferred diagnoses based on warfarin prescriptions without prior thromboembolic disease. In order to define non-valvular AF we then excluded individuals with a record of mitral valve disease, rheumatic mitral regurgitation, and prosthetic mitral, aortic or unspecified valve replacements, ${ }^{21}$ based on 45 Read codes, 9 ICD-10 codes and 11 operation and procedure codes (see online supplementary table S1 for the code list).

\section{$\mathrm{CHA}_{2} \mathrm{DS}_{2}$-VASc}

We generated baseline $\mathrm{CHA}_{2} \mathrm{DS}_{2}$-VASc scores for each individual by assigning 1 or 2 points for each stroke risk factor. Risk factors were defined according to existing CALIBER phenotypes (available at caliberresearch.org), which use all available clinical information across the linked primary and secondary care records. In brief, age and sex were obtained from general practice registration information; congestive heart failure, diabetes mellitus (types I, II and unclassified), history of stroke or thromboembolism (stroke, transient ischaemic attack or systemic embolism), and vascular disease (myocardial infarction (MI) or peripheral artery disease (PAD)) from clinical diagnosis codes; and hypertension from diagnosis codes, two or more values of systolic or diastolic blood pressure measurements above UK diagnostic thresholds of $140 / 90 \mathrm{~mm} \mathrm{Hg},{ }^{22}$ or through repeat prescriptions for blood pressure lowering medications.

\section{Warfarin}

We considered warfarin use throughout the entire study period and extracted information on prescriptions and international normalised ratio (INR) tests from primary care records. Prescriptions data include drug type and date of administration but do not have information on pharmacy collections. Individuals were considered to be using warfarin continuously during follow-up if a prescription or INR test was administered every 30 days. This allowed each individual's follow-up time to be divided into periods with and without use of warfarin. ${ }^{23}$

\section{Follow-up and end points}

Individuals entered the study at their earliest coded diagnosis of AF during January 1998 and March 2010, provided they were aged 18 years and over and with a minimum of 1 year of continuous registration at a general practice with acceptable data recording standards. We followed individuals for clinical diagnoses of IS and unclassified strokes, and for haemorrhagic strokes (HSs) (intracerebral and subarachnoid haemorrhage) as recorded in primary or secondary care and mortality registry records. ISs and unclassified strokes were combined, as it has previously 
been shown that $87 \%$ of all strokes are ischaemic. ${ }^{24}$ A clearance period of 2 weeks was imposed from date of recorded AF diagnosis, such that any stroke occurring during this time was attributed to baseline risk and not counted as an end point. The rationale is that AF is commonly first detected when an individual presents with a complication, such as stroke. ${ }^{25}$ Clearance periods are also imperative when analysing linked EHRs to avoid double counting, as the same event can be recorded more than once, and in multiple data sources. ${ }^{26}$ Total follow-up time for each individual was calculated as the number of days from the end of the clearance period to the point of censoring. Individuals were censored in the event of an IS or HS end point, death (from a cause other than a stroke end point), transfer out of general practice, or last date of data collection.

\section{Data analysis}

We compared baseline $\mathrm{CHA}_{2} \mathrm{DS}_{2}$-VASc risk factors in individuals with initial record of diagnosis in primary and secondary care using the Student's t-test or $\chi^{2}$ test, and these are presented as proportions, means (SD) and medians (range, IQR), as appropriate. We assessed the completeness of recording $\mathrm{CHA}_{2} \mathrm{DS}_{2}$-VASc risk factors in each data source using absolute proportions, that is, number (\%) of total cases captured in primary care records, and in secondary care records, compared with both data sources linked. We calculated IRs and 95\% CIs per 100 person-years (PYs) (IR (95\% CI)/100 PY) for IS and HS by dividing the number of end points by the accrued number of PYs. We assessed whether IRs were robust by comparing with estimates adjusted for propensity score quintiles. This accounts for whether individuals were more likely or less likely to receive treatment with warfarin. We conducted NCB analyses comparing number of ISs avoided, against number of HSs experienced per 100 PYs of warfarin use (NCB (95\% CI)/100 PY). We used the formula: (IS rate without warfarin IS rate with warfarin $)-1.5$ (HS rate $_{\text {with }}$ warfarin $-\mathrm{HS}$ rate without warfarin $_{1}$, whereby a positive estimate indicates a treatment benefit, and a negative estimate indicates treatment harm. ${ }^{27}$ We regarded the NCB as significant if the $95 \%$ CI did not span both the positive and negative scales. All analyses were conducted in Stata/SE V.13 and figures were generated in R (V.3.2.0).

\section{RESULTS}

\section{Population characteristics}

Population overall

The overall study population comprised 70206 individuals with non-valvular AF with median age of 77.9 years (range: 18.0108.7, IQR: 15.1), and median follow-up of 2.20 years (range: 0.03-12.2, IQR: 4.2). Of the individuals 34286 (48.8\%) were women, and $2486(3.5 \%)$ had $\mathrm{CHA}_{2} \mathrm{DS}_{2}$-VASc $=0,5637(8.0 \%)$ had $\mathrm{CHA}_{2} \mathrm{DS}_{2}-\mathrm{VASc}=1$ and $9339(13.3 \%)$ had $\mathrm{CHA}_{2} \mathrm{DS}_{2^{-}}$ $\mathrm{VASc}=2$. The mean (SD) $\mathrm{CHA}_{2} \mathrm{DS}_{2}$-VASc score of the overall population was $3.7(1.8)$.

Individuals with initial record of diagnosis in primary versus secondary care

Of the individuals 29568 (42.1\%) had initial record of diagnosis of AF in primary care, and 40638 (57.9\%) had initial record of diagnosis in secondary care. Individuals with initial record of diagnosis in secondary care were older (median (IQR) age: 79.1 (15.0) years vs 76.5 (14.8) years), more likely to be female $(50.1 \%$ vs $47.1 \%)$ and were less likely to have $\mathrm{CHA}_{2} \mathrm{DS}_{2^{-}}$ $\mathrm{VASc}=0(2.9 \%$ vs $4.4 \%), \mathrm{CHA}_{2} \mathrm{DS}_{2}-\mathrm{VASc}=1(6.6 \%$ vs $10.1 \%)$ or $\mathrm{CHA}_{2} \mathrm{DS}_{2}$-VASc $=2(11.1 \%$ vs $6.6 \%)$ than those with initial record of diagnosis in primary care. The mean (SD) $\mathrm{CHA}_{2} \mathrm{DS}_{2^{-}}$
VASc score among individuals with initial record of diagnosis of AF in primary care compared with secondary care was 3.3 (1.7) vs 4.0 (1.8). As table 1 shows, individuals with initial record of diagnosis in secondary care had a higher proportion of all $\mathrm{CHA}_{2} \mathrm{DS}_{2}$-VASc risk factors.

Individuals with versus without use of warfarin

Of the individuals 30067 (42.8\%) underwent at least one period of warfarin use during follow-up; $50.1 \%$ of these had initial record of diagnosis in primary care $(n=15077)$ and $49.9 \%$ had initial record of diagnosis in secondary care $(n=14990)$. Individuals without use of warfarin were older (median (IQR) age: 80.7 (15.2) years vs 74.9 (13.4) years) and had a higher proportion of heart failure, but there was no difference in diagnosed hypertension, vascular disease (MI or PAD), diabetes and previous strokes, when compared with those with at least one period of warfarin use (see online supplementary table S2).

\section{Men versus women}

Women were older (median (IQR) age: 80.8 (13.3) years vs 74.9 (15.9) years) and had a higher proportion of heart failure, hypertension and previous strokes, while vascular disease (MI and PAD) and diabetes were more common in men (see online supplementary table S3).

\section{Completeness of risk factors and reclassification of $\mathrm{CHA}_{2} \mathrm{DS}_{2}$-VASc scores}

The completeness of recording $\mathrm{CHA}_{2} \mathrm{DS}_{2}$-VASc risk factors in primary and secondary care records ranged from $40.4 \%$ to $73.7 \%$ complete in secondary care records, and from $69.1 \%$ to $99.0 \%$ in primary care records (see online supplementary table S4 and figure S1). Among individuals with initial record of diagnosis in secondary care, $975(45.2 \%)$ were reclassified from $\mathrm{CHA}_{2} \mathrm{DS}_{2}-\mathrm{VASc}=0$ to $\mathrm{CHA}_{2} \mathrm{DS}_{2}-\mathrm{VASc} \geq 1$ and 2172 (53.7\%) from $\mathrm{CHA}_{2} \mathrm{DS}_{2}-\mathrm{VASc}=1$ to $\mathrm{CHA}_{2} \mathrm{DS}_{2}-\mathrm{VASc} \geq 2$ when scores were calculated using linked primary-secondary care records. Only $15(1.1 \%)$ individuals with initial record of diagnosis in primary care were reclassified from $\mathrm{CHA}_{2} \mathrm{DS}_{2}-\mathrm{VASc}=0$ to $\mathrm{CHA}_{2} \mathrm{DS}_{2}-\mathrm{VASc} \geq 1$ and 81 (2.7\%) from $\mathrm{CHA}_{2} \mathrm{DS}_{2}-\mathrm{VAS} \mathrm{c}=1$ to $\mathrm{CHA}_{2} \mathrm{DS}_{2}-\mathrm{VASc} \geq 2$. For $\mathrm{CHA}_{2} \mathrm{DS}_{2}$-VASc scores calculated based on primary and secondary care records compared with both data sources linked, see online supplementary table S5.

\section{Stroke incidence}

IS incidence in individuals with initial record of diagnosis in primary or secondary care

Seven thousand and five ISs occurred over 216446 PYs, with IR (95\% CI)/100 PY of 3.2 (3.2 to 3.3). Compared with individuals with initial record of diagnosis in secondary care, those in primary care had lower overall IS incidence (IR (95\% CI)/ 100 PY: 2.3 (2.2 to 2.4 ) vs 4.3 (4.2 to 4.4$)$, p value=0.00), however as figure 2 shows there were no differences in incidence at $\mathrm{CHA}_{2} \mathrm{DS}_{2}$-VASc $=0$ (IR $(95 \% \mathrm{CI}) / 100 \mathrm{PY}: 0.2(0.1$ to 0.3$)$ vs $0.3(0.2$ to 0.5$), \mathrm{p}$ value $=0.16), \mathrm{CHA}_{2} \mathrm{DS}_{2}-\mathrm{VASc}=1 \quad(\mathrm{IR} \quad(95 \%$ CI)/100 PY: $0.6(0.4$ to 0.7$)$ vs $0.7(0.6$ to 0.9$)$, $\mathrm{p}$ value $=0.08)$ or $\mathrm{CHA}_{2} \mathrm{DS}_{2}-\mathrm{VASc}=2(\mathrm{IR}(95 \% \mathrm{CI}) / 100 \mathrm{PY}: 1.1$ (1.00 to 1.3$)$ vs 1.4 (1.2 to 1.6$), \mathrm{p}$ value $=0.05)$. IRs in individuals with initial record of diagnosis in primary or in secondary care across all $\mathrm{CHA}_{2} \mathrm{DS}_{2}$-VASc scores are provided in table 2 .

\section{IS incidence by warfarin use}

One thousand and fifteen (14.5\%) ISs occurred over 59006 PYs of warfarin use and 5990 (85.5\%) over 157439 PYs of no 
Table 1 Comparison of baseline $\mathrm{CHA}_{2} \mathrm{DS}_{2}$-VASc risk factors in individuals with initial record of diagnosis in primary or secondary care

\begin{tabular}{|c|c|c|c|c|c|c|}
\hline \multirow[b]{4}{*}{ Number of individuals } & \multicolumn{4}{|c|}{ Initial record of diagnosis } & & \\
\hline & \multirow{2}{*}{\multicolumn{2}{|c|}{$\begin{array}{l}\text { Primary care } \\
29568\end{array}$}} & \multirow{2}{*}{\multicolumn{2}{|c|}{$\begin{array}{l}\text { Secondary care } \\
40638\end{array}$}} & \multirow{2}{*}{\multicolumn{2}{|c|}{$\begin{array}{l}\text { Population overall } \\
70206\end{array}$}} \\
\hline & & & & & & \\
\hline & $\mathbf{N}$ & Per cent & $\mathbf{N}$ & Per cent & $\mathbf{N}$ & Per cent \\
\hline Congestive heart failure & 4768 & 16.1 & 12664 & 31.2 & 17432 & 24.8 \\
\hline Hypertension & 23946 & 81.0 & 33817 & 83.2 & 57763 & 82.3 \\
\hline Diagnosis & 16616 & 56.2 & 25273 & 62.2 & 41889 & 59.7 \\
\hline Blood pressure medication & 20979 & 71.0 & 30164 & 74.2 & 51143 & 72.9 \\
\hline Blood pressure measures & 17281 & 58.4 & 22329 & 55.0 & 39610 & 56.4 \\
\hline Age $\geq 75$ years $^{2}$ & 16318 & 55.2 & 25872 & 63.7 & 42190 & 60.1 \\
\hline Diabetes & 3316 & 11.2 & 6673 & 16.4 & 9989 & 14.2 \\
\hline $\begin{array}{l}\text { Stroke/transient ischaemic attack/ } \\
\text { systemic embolism² }\end{array}$ & 3887 & 13.2 & 8938 & 22.0 & 12825 & 18.3 \\
\hline Vascular disease & 4049 & 13.7 & 9783 & 24.1 & 13832 & 19.7 \\
\hline Myocardial infarction & 2635 & 8.9 & 6950 & 17.1 & 9585 & 13.7 \\
\hline Peripheral vascular disease & 1776 & 6.0 & 3927 & 9.7 & 5703 & 8.1 \\
\hline Age $65-74$ years & 7744 & 26.2 & 8552 & 21.0 & 16296 & 23.2 \\
\hline Sex category (female) & 13930 & 47.1 & 20356 & 50.1 & 34286 & 48.8 \\
\hline \multicolumn{7}{|l|}{$\mathrm{CHA}_{2} \mathrm{DS}_{2}$-VASc scores } \\
\hline 0 & 1305 & 4.4 & 1181 & 2.9 & 2486 & 3.5 \\
\hline 1 & 2972 & 10.1 & 2665 & 6.6 & 5637 & 8.0 \\
\hline 2 & 4820 & 16.3 & 4519 & 11.1 & 9339 & 13.3 \\
\hline 3 & 6663 & 22.5 & 7107 & 17.5 & 13770 & 19.6 \\
\hline 4 & 7332 & 24.8 & 9578 & 23.6 & 16910 & 24.1 \\
\hline 5 & 3712 & 12.6 & 7514 & 18.5 & 11226 & 16.0 \\
\hline 6 & 1866 & 6.3 & 4906 & 12.1 & 6772 & 9.7 \\
\hline 7 & 724 & 2.5 & 2341 & 5.8 & 3065 & 4.4 \\
\hline 8 & 156 & 0.5 & 707 & 1.7 & 863 & 1.2 \\
\hline 9 & 18 & 0.1 & 120 & 0.3 & 138 & 0.2 \\
\hline
\end{tabular}

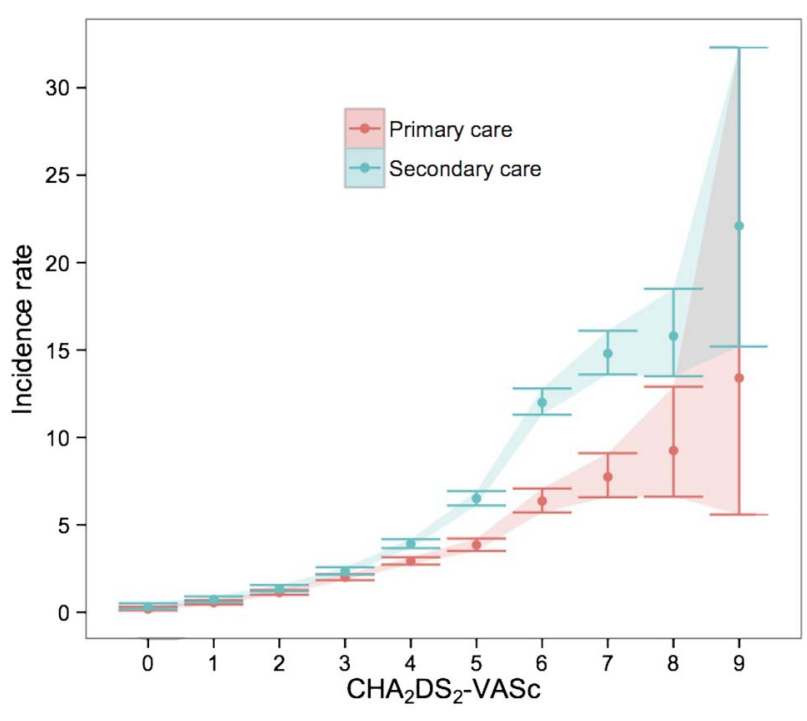

Number of individuals with initial record of diagnosis in primary care:

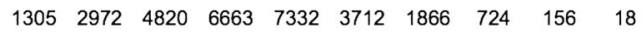
Number of individuals with initial record of diagnosis in secondary care: $\begin{array}{llllllllll}1181 & 2665 & 4519 & 7107 & 9578 & 7514 & 4906 & 2341 & 707 & 120\end{array}$

Figure 2 Incidence rates $(95 \% \mathrm{Cls})$ per 100 person-years of ischaemic stroke by $\mathrm{CHA}_{2} \mathrm{DS}_{2}$-VASC scores in individuals with initial record of diagnosis in primary or secondary care. warfarin use. IRs were lower with warfarin use (IR (95\% CI)/ 100 PY: 1.7 (1.6 to 1.8 ) vs 3.8 (3.7 to 3.9$)$, p value $=0.00$ ), with an IR ratio $(95 \% \mathrm{CI})$ of $0.5(0.4$ to 0.5$)$. For $\mathrm{CHA}_{2} \mathrm{DS}_{2}-\mathrm{VASc}=0$, $\mathrm{CHA}_{2} \mathrm{DS}_{2}-\mathrm{VAS} \mathrm{c}=1$ and $\mathrm{CHA}_{2} \mathrm{DS}_{2}-\mathrm{VASc}=2$, IRs with versus without use of warfarin were (IR (95\% CI)/100 PY: 0.4 (0.2 to $0.8)$ vs 0.2 (0.1 to 0.3$)$, p value $=0.16)$, (IR (95\% CI)/100 PY: 0.4 (0.3 to 0.7$)$ vs $0.7(0.6$ to 0.8$)$, p value $=0.03)$ and (IR $(95 \% \mathrm{CI}) /$ 100 PY: 0.8 (0.7 to 1.0$)$ vs 1.4 (1.3 to 1.6$)$, p value $=0.00)$. As figures 3 and 4 show IRs were lower with use of warfarin from $\mathrm{CHA}_{2} \mathrm{DS}_{2}$-VASc $\geq 2$ in men (IR (95\% CI)/100 PY: 0.9 (0.7 to 1.1$)$ vs 1.7 (1.5 to 1.9$)$, $\mathrm{p}$ value $=0.00)$, and from $\mathrm{CHA}_{2} \mathrm{DS}_{2}-\mathrm{VASc} \geq 3$ in women (IR (95\% CI)/100 PY: 0.7 (0.5 to 1.0$)$ vs 2.3 (2.0 to $2.5)$, $\mathrm{p}$ value $=0.00)$. IRs by sex and use of warfarin across all $\mathrm{CHA}_{2} \mathrm{DS}_{2}$-VASc scores are provided in table 3 . IRs adjusted for propensity score quintiles were consistent with the unadjusted estimates (see online supplementary table S6).

NCB of warfarin

Nine hundred and six HSs occurred over 224777 PYs. The overall NCB of warfarin was 1.9 (1.8 to 2.1) ISs avoided per 100 PYs. For $\mathrm{CHA}_{2} \mathrm{DS}_{2}-\mathrm{VASc}_{\mathrm{c}}=0, \quad \mathrm{CHA}_{2} \mathrm{DS}_{2}-\mathrm{VASc}=1$ and $\mathrm{CHA}_{2} \mathrm{DS}_{2}-\mathrm{VASc}=2$, NCB was $(\mathrm{NCB}(95 \% \mathrm{CI}) / 100 \mathrm{PY}:-0.3$ (-0.8 to 0.1$)$ ), (NCB (95\% CI)/100 PY: $0.1(-0.2$ to 0.4$))$ and (NCB (95\% CI)/100 PY: 0.2 (-0.1 to 0.6$)$ ), respectively. A significant positive $\mathrm{NCB}$ was observed from $\mathrm{CHA}_{2} \mathrm{DS}_{2}-\mathrm{VASc} \geq 2$ in men (NCB (95\% CI)/100 PY: 0.5 (0.1 to 0.9$)$ ) and from 
Table 2 Incidence rates $(95 \% \mathrm{Cls})$ per 100 person-years of ischaemic stroke by $\mathrm{CHA}_{2} \mathrm{DS}_{2}$-VASC scores in individuals with initial record of diagnosis in primary or secondary care

\begin{tabular}{|c|c|c|c|c|c|c|c|}
\hline & \multicolumn{4}{|c|}{ Initial record of diagnosis } & \multirow[b]{3}{*}{$p$ Value } & \multirow{2}{*}{\multicolumn{2}{|c|}{ Population overall }} \\
\hline & \multicolumn{2}{|c|}{ Primary care } & \multicolumn{2}{|c|}{ Secondary care } & & & \\
\hline & Events & Rate & Events & Rate & & Events & Rate \\
\hline \multicolumn{8}{|c|}{$\mathrm{CHA}_{2} \mathrm{DS}_{2}$-VASc scores } \\
\hline 0 & 12 & 0.2 (0.1 to 0.3$)$ & 16 & $0.3(0.2$ to 0.5$)$ & 0.16 & 28 & $0.2(0.2$ to 0.4$)$ \\
\hline 1 & 77 & $0.6(0.4$ to 0.7$)$ & 76 & $0.7(0.6$ to 0.9$)$ & 0.08 & 153 & $0.6(0.5$ to 0.7$)$ \\
\hline 2 & 244 & 1.1 (1.0 to 1.3$)$ & 209 & 1.4 (1.2 to 1.6$)$ & 0.05 & 453 & $1.2(1.1$ to 1.3$)$ \\
\hline 3 & 528 & 2.0 (1.8 to 2.2 ) & 485 & 2.4 (2.2 to 2.6$)$ & 0.01 & 1013 & 2.2 (2.0 to 2.3 ) \\
\hline 4 & 766 & 2.9 (2.7 to 3.2$)$ & 907 & 3.9 (3.7 to 4.2$)$ & 0.00 & 1673 & $3.4(3.2$ to 3.6$)$ \\
\hline 5 & 450 & 3.9 (3.5 to 4.2 ) & 966 & 6.5 (6.1 to 6.9$)$ & 0.00 & 1416 & 5.3 (5.1 to 5.6$)$ \\
\hline 6 & 332 & 6.4 (5.7 to 7.1$)$ & 1028 & $12.0(11.3$ to 12.8$)$ & 0.00 & 1360 & 9.9 (9.4 to 10.4$)$ \\
\hline 7 & 146 & 7.7 (6.6 to 9.1$)$ & 546 & 14.8 (13.6 to 16.1$)$ & 0.00 & 692 & 12.4 (11.5 to 13.3$)$ \\
\hline 8 & 34 & $9.3(6.6$ to 12.9$)$ & 151 & $15.8(13.5$ to 18.5$)$ & 0.00 & 185 & 13.9 (12.1 to 16.1$)$ \\
\hline 9 & 5 & 13.4 (5.6 to 32.3$)$ & 27 & 22.1 (15.2 to 32.3$)$ & 0.31 & 32 & 20.0 (14.2 to 28.4$)$ \\
\hline $0-9$ & 2594 & 2.3 (2.2 to 2.4$)$ & 4411 & 4.3 (4.2 to 4.42 ) & 0.00 & 7005 & 3.2 (3.2 to 3.3 ) \\
\hline
\end{tabular}

Bold text is used to differentiate the rates among individual scores $0,1,2, \ldots, 9$, from all scores 0 to 9 combined.

$\mathrm{CHA}_{2} \mathrm{DS}_{2}-\mathrm{VASc} \geq 3$ in women $(\mathrm{NCB}(95 \% \mathrm{CI}) / 100 \mathrm{PY}: 1.5(1.1$ to 1.9)). $\mathrm{NCB}$ estimates across all $\mathrm{CHA}_{2} \mathrm{DS}_{2}$-VASc scores are provided in table 4 .

\section{DISCUSSION}

We conducted the first large-scale nationally representative study of the potential benefits and harms of warfarin in individuals with AF across stroke risk and across primary and secondary care, and had two major findings. First, we confirmed that $\mathrm{CHA}_{2} \mathrm{DS}_{2}$-VASc accurately stratifies stroke risk in individuals with initial record of diagnosis in primary and secondary care, however clinical information recorded in both primary and secondary care must be considered in order to correctly assign $\mathrm{CHA}_{2} \mathrm{DS}_{2}$-VASc scores. Second, in individuals who were truly $\mathrm{CHA}_{2} \mathrm{DS}_{2}-\mathrm{VASc}=1$, the absolute risk of IS $(0.4$ (0.3 to 0.7$)$ with warfarin, and 0.7 (0.6 to 0.8$)$ without warfarin) was relatively

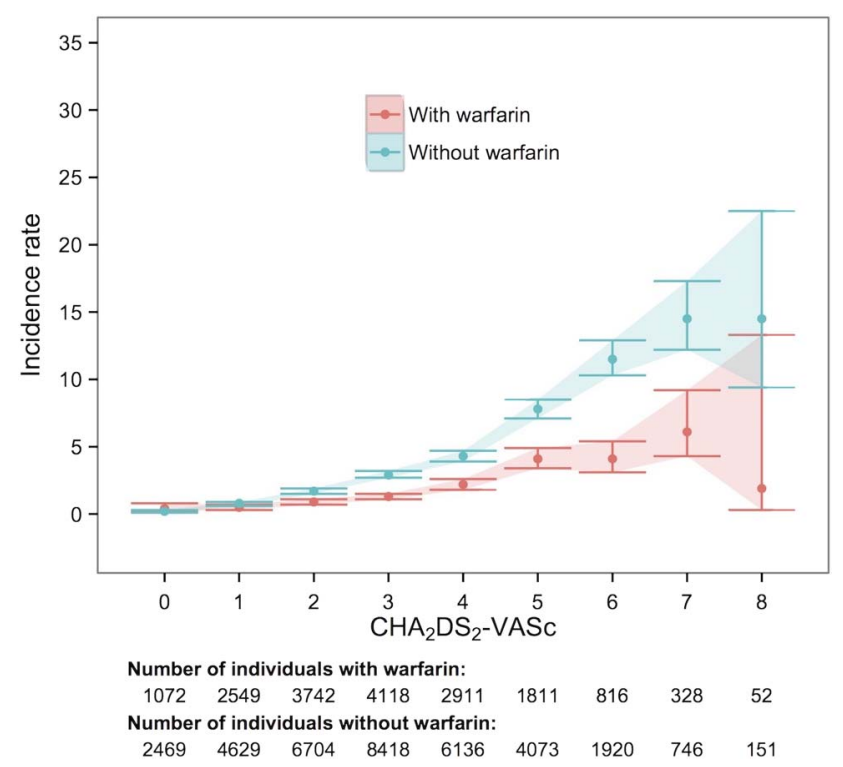

Figure 3 Incidence rates ( $95 \% \mathrm{Cls}$ ) per 100 person-years of ischaemic stroke in men by $\mathrm{CHA}_{2} \mathrm{DS}_{2}$-VASC scores, and use of warfarin. Individuals could contribute follow-up time to periods with and without warfarin. low and similar to the original derivation cohort of the $\mathrm{CHA}_{2} \mathrm{DS}_{2}$-VASc score, ${ }^{1}$ and the $\mathrm{NCB}$ of warfarin was positive but non-significant $(0.1(-0.2$ to 0.4$))$. We therefore found insufficient evidence to support anticoagulation with warfarin in individuals with $\mathrm{CHA}_{2} \mathrm{DS}_{2}-\mathrm{VASc}=1$.

\section{Findings in context}

Our IS IR of 0.7 (0.6 to 0.8 ) for $\mathrm{CHA}_{2} \mathrm{DS}_{2}$-VASc $=1$ without warfarin is low compared with previous reports (see online supplementary table S7) although consistent with the levels of uncertainty in a recent systematic review which reported an annual rate of $1.6 \%$ but with wide CIs (0\% to $3.23 \%)$. Three lines of evidence from sensitivity analyses in men with $\mathrm{CHA}_{2} \mathrm{DS}_{2}$-VASc $=1$ (see online supplementary table S8) suggest that our estimates of stroke incidence are likely to be robust and offer reasons why they may differ from previous reports. First,

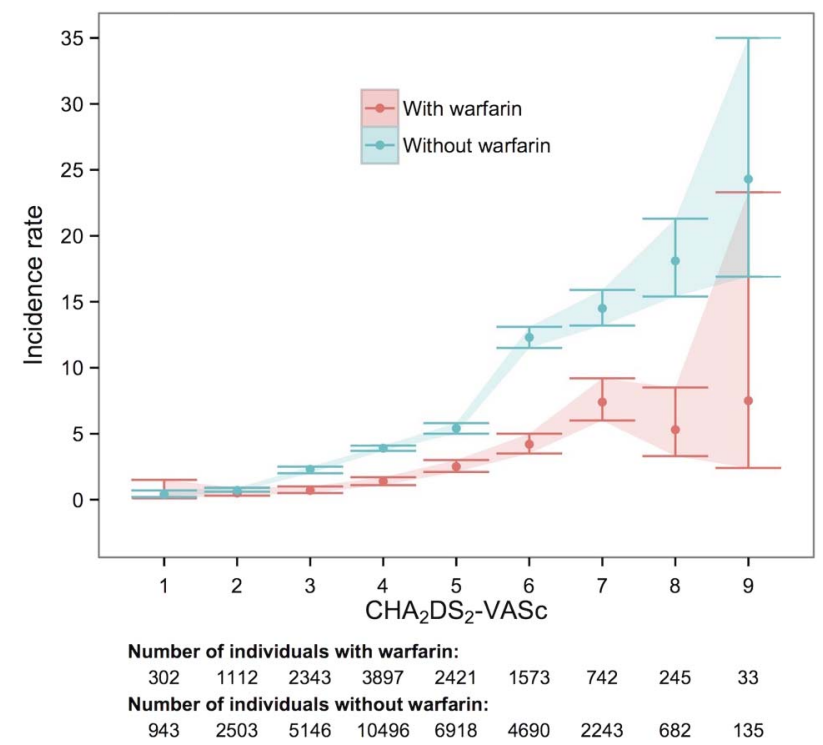

Figure 4 Incidence rates (95\% Cls) per 100 person-years of ischaemic stroke in women by $\mathrm{CHA}_{2} \mathrm{DS}_{2}$-VASC scores, and use of warfarin. Individuals could contribute follow-up time to periods with and without warfarin. 
Table 3 Incidence rates $(95 \% \mathrm{Cls})$ per 100 person-years of ischaemic stroke by $\mathrm{CHA}_{2} \mathrm{DS}_{2}$-VASC scores, sex and use of warfarin

\begin{tabular}{|c|c|c|c|c|c|c|c|}
\hline & \multicolumn{2}{|c|}{ With warfarin } & \multicolumn{2}{|c|}{ Without warfarin } & \multirow[b]{2}{*}{$\mathrm{p}$ Value } & \multicolumn{2}{|c|}{ Population overall } \\
\hline & Events & Rate & Events & Rate & & Events & Rate \\
\hline \multicolumn{8}{|c|}{$\mathrm{CHA}_{2} \mathrm{DS}_{2}$-VASC scores } \\
\hline \multicolumn{8}{|c|}{ Overall population } \\
\hline 0 & 7 & $0.4(0.2$ to 0.8$)$ & 21 & $0.2(0.1$ to 0.3$)$ & 0.23 & 28 & $0.2(0.2$ to 0.4$)$ \\
\hline 1 & 27 & $0.4(0.3$ to 0.7$)$ & 126 & 0.7 (0.6 to 0.8 ) & 0.03 & 153 & 0.6 (0.5 to 0.7$)$ \\
\hline 2 & 87 & $0.8(0.7$ to 1.0$)$ & 366 & 1.4 (1.3 to 1.6$)$ & 0.00 & 453 & $1.2(1.1$ to 1.3$)$ \\
\hline 3 & 144 & 1.0 (0.9 to 1.2$)$ & 869 & 2.6 (2.5 to 2.8$)$ & 0.00 & 1013 & $2.2(2.0$ to 2.3$)$ \\
\hline 4 & 226 & 1.7 (1.5 to 2.0$)$ & 1447 & 4.0 (3.8 to 4.2 ) & 0.00 & 1673 & 3.4 (3.2 to 3.6$)$ \\
\hline 5 & 233 & 3.2 (2.8 to 3.6) & 1183 & 6.2 (5.8 to 6.5 ) & 0.00 & 1416 & 5.3 (5.1 to 5.6 ) \\
\hline 6 & 159 & 4.2 (3.6 to 4.8 ) & 1201 & 12.1 (11.4 to 12.8$)$ & 0.00 & 1360 & 9.9 (9.4 to 10.4$)$ \\
\hline 7 & 111 & 7.1 (5.9 to 8.6 ) & 581 & 14.5 (13.4 to 15.7$)$ & 0.00 & 692 & 12.4 (11.5 to 13.4$)$ \\
\hline 8 & 18 & 4.8 (3.0 to 7.6 ) & 167 & 17.6 (15.1 to 20.5$)$ & 0.00 & 185 & 14.0 (12.1 to 16.2$)$ \\
\hline 9 & 3 & 7.5 (2.4 to 23.3$)$ & 29 & 24.3 (16.9 to 35.0$)$ & 0.03 & 32 & 20.1 (14.2 to 28.4 ) \\
\hline $0-9$ & 1015 & 1.7 (1.6 to 1.8 ) & 5990 & 3.8 (3.7 to 3.9 ) & 0.00 & 7005 & 3.2 (3.2 to 3.3 ) \\
\hline \multicolumn{8}{|l|}{ Men } \\
\hline 0 & 7 & $0.4(0.2$ to 0.8$)$ & 21 & $0.2(0.1$ to 0.3$)$ & 0.23 & 28 & $0.2(0.2$ to 0.4$)$ \\
\hline 1 & 25 & $0.5(0.3$ to 0.7$)$ & 112 & $0.8(0.6$ to 0.9$)$ & 0.01 & 137 & 0.7 (0.6 to 0.8$)$ \\
\hline 2 & 75 & $0.9(0.7$ to 1.1$)$ & 306 & 1.7 (1.5 to 1.9$)$ & 0.00 & 381 & 1.5 (1.3 to 1.6$)$ \\
\hline 3 & 106 & $1.3(1.1$ to 1.5$)$ & 550 & 2.9 (2.7 to 3.2$)$ & 0.00 & 656 & $2.4(2.2$ to 2.6$)$ \\
\hline 4 & 119 & 2.2 (1.8 to 2.6$)$ & 489 & 4.3 (3.9 to 4.7 ) & 0.00 & 608 & 3.6 (3.3 to 3.9$)$ \\
\hline 5 & 122 & 4.1 (3.4 to 4.9 ) & 491 & 7.8 (7.1 to 8.5$)$ & 0.00 & 613 & $6.6(6.1$ to 7.1$)$ \\
\hline 6 & 51 & 4.1 (3.1 to 5.4 ) & 312 & 11.5 (10.3 to 12.9$)$ & 0.00 & 363 & 9.2 (8.3 to 10.1 ) \\
\hline 7 & 27 & 6.1 (4.3 to 9.2 ) & 129 & 14.5 (12.2 to 17.3$)$ & 0.00 & 156 & 11.9 (10.1 to 13.9$)$ \\
\hline 8 & 1 & $1.9(0.3$ to 13.3$)$ & 20 & 14.5 (9.4 to 22.5$)$ & 0.01 & 21 & 11.0 (7.2 to 16.8 ) \\
\hline $0-8$ & 533 & $1.6(1.4$ to 1.7$)$ & 2430 & 2.9 (2.8 to 3.1$)$ & 0.00 & 2963 & 2.5 (2.4 to 2.6 ) \\
\hline \multicolumn{8}{|c|}{ Women } \\
\hline 1 & 2 & $0.4(0.1$ to 1.5$)$ & 14 & $0.4(0.2$ to 0.7$)$ & 0.97 & 16 & $0.4(0.3$ to 0.7$)$ \\
\hline 2 & 12 & $0.5(0.3$ to 0.9$)$ & 60 & 0.7 (0.6 to 0.9$)$ & 0.24 & 72 & 0.7 (0.5 to 0.8$)$ \\
\hline 3 & 38 & $0.7(0.5$ to 1.0$)$ & 319 & 2.3 (2.0 to 2.5$)$ & 0.00 & 357 & $1.8(1.6$ to 2.0$)$ \\
\hline 4 & 107 & $1.4(1.1$ to 1.7$)$ & 958 & 3.9 (3.7 to 4.1$)$ & 0.00 & 1065 & 3.3 (3.1 to 3.5 ) \\
\hline 5 & 111 & $2.5(2.1$ to 3.0$)$ & 692 & 5.4 (5.0 to 5.8 ) & 0.00 & 803 & $4.7(4.4$ to 5.0$)$ \\
\hline 6 & 108 & 4.2 (3.5 to 5.0$)$ & 889 & $12.3(11.5$ to 13.1$)$ & 0.00 & 997 & 10.2 (9.5 to 10.8$)$ \\
\hline 7 & 84 & 7.4 (6.0 to 9.2$)$ & 452 & 14.5 (13.2 to 15.9$)$ & 0.00 & 536 & 12.6 (11.6 to 13.7$)$ \\
\hline 8 & 17 & 5.3 (3.3 to 8.5 ) & 147 & 18.1 (15.4 to 21.3$)$ & 0.00 & 164 & 14.5 (12.4 to 16.9$)$ \\
\hline 9 & 3 & 7.5 (2.4 to 23.3$)$ & 29 & 24.3 (16.9 to 35.0$)$ & 0.03 & 32 & 20.1 (14.2 to 28.4 ) \\
\hline $1-9$ & 482 & 2.0 (1.8 to 2.1$)$ & 3560 & 4.8 (4.6 to 4.9$)$ & 0.00 & 4042 & 4.1 (3.9 to 4.2 ) \\
\hline
\end{tabular}

as found in our main analysis, secondary care records underestimate stroke risk in half of individuals, and therefore previous studies which have predominantly focused on secondary care populations are likely to be biased by misclassification of $\mathrm{CHA}_{2} \mathrm{DS}_{2}$-VASc scores. In a sensitivity analysis of men with $\mathrm{CHA}_{2} \mathrm{DS}_{2}$-VASc $=1$ according to secondary care records (which included 53\% who were truly $\mathrm{CHA}_{2} \mathrm{DS}_{2}$-VASc $\geq 2$ ), we found an IR of 1.4 (1.2 to 1.5), which is twice as high as the rate found for men who were truly $\mathrm{CHA}_{2} \mathrm{DS}_{2}-\mathrm{VASc}=1$ (0.7 (0.6 to 0.8$\left.)\right)$ and similar to the meta-analysed rate found in the recent systematic review (1.6 (0 to 3.23)). Importantly, we confirm that if $\mathrm{CHA}_{2} \mathrm{DS}_{2}$-VASc risk is underestimated then stroke rates at the lower end of the $\mathrm{CHA}_{2} \mathrm{DS}_{2}$-VASc scale are overestimated, which has implications on treatment decisions. Second, Friberg, et al $\mathrm{l}^{25}$ reported that variation in the literature also exists because of differences in the way stroke is defined, and that a 44\% higher IR is observed when including wider thromboembolic end points. We also confirmed this in a sensitivity analysis, and found that for men with $\mathrm{CHA}_{2} \mathrm{DS}_{2}$-VASc $=1$, the IR doubled from $0.7(0.6$ to 0.8$)$ to 1.4 (1.2 to 1.5 ) when systemic embolism, pulmonary embolism and transient ischaemic attacks were included as a composite end point. Third, differences in previously reported stroke rates at $\mathrm{CHA}_{2} \mathrm{DS}_{2}-\mathrm{VASc}=1$ may exist because not all 1-point scoring risk factors (heart failure, hypertension, diabetes mellitus, vascular disease, age 65-74 years, female sex) confer the same stroke risk. ${ }^{28}$ In sensitivity analyses, we found that age 65-74 years conferred the highest stroke risk with IR of 1.2 (0.9 to 1.5). Thus, population-based IRs of $\mathrm{CHA}_{2} \mathrm{DS}_{2}-\mathrm{VAS} c=1$ will depend upon the distribution of 1-point scoring risk factors within the population.

Unlike the recent systematic review, our findings with regard to $\mathrm{CHA}_{2} \mathrm{DS}_{2}-\mathrm{VASc}=1$ are supported by $\mathrm{NCB}$ analyses. To our knowledge, this is the first NCB analysis of warfarin to date that includes both individuals with initial record of diagnosis in primary and secondary care. We found a positive but nonsignificant treatment benefit of warfarin in individuals with $\mathrm{CHA}_{2} \mathrm{DS}_{2}-\mathrm{VASc}=1(0.1(-0.2$ to 0.4$))$, and therefore insufficient evidence to support anticoagulation with warfarin in these individuals. Existing NCB analyses of warfarin have predominantly focused on individuals with initial record of diagnosis in secondary care, but have also shown an unclear benefit of treatment at $\mathrm{CHA}_{2} \mathrm{DS}_{2}-\mathrm{VASc}=1$, including in both the nationwide 
Table 4 Net clinical benefit (95\% Cls) per 100 person-years with warfarin, by $\mathrm{CHA}_{2} \mathrm{DS}_{2}$-VASC scores and sex

\begin{tabular}{|c|c|c|c|}
\hline & \multicolumn{2}{|l|}{ Total stroke events } & \multirow[b]{2}{*}{ Net clinical benefit } \\
\hline & Ischaemic stroke & Haemorrhagic stroke & \\
\hline \multicolumn{4}{|c|}{$\mathrm{CHA}_{2} \mathrm{DS}_{2}$-VASc scores } \\
\hline \multicolumn{4}{|c|}{ Overall population } \\
\hline 0 & 28 & 8 & $-0.3(-0.8$ to 0.1$)$ \\
\hline 1 & 153 & 54 & $0.1(-0.2$ to 0.4$)$ \\
\hline 2 & 453 & 95 & $0.2(-0.1$ to 0.6$)$ \\
\hline 3 & 1013 & 165 & 1.5 (1.2 to 1.8$)$ \\
\hline 4 & 1673 & 237 & 2.2 (1.8 to 2.6 ) \\
\hline 5 & 1416 & 180 & 3.2 (2.6 to 3.8$)$ \\
\hline 6 & 1360 & 104 & 7.7 (6.7 to 8.8 ) \\
\hline 7 & 692 & 45 & 7.2 (5.2 to 9.1$)$ \\
\hline 8 & 185 & 18 & 12.8 (8.9 to 16.9$)$ \\
\hline 9 & 32 & 0 & $16.8(1.8$ to 31.5$)$ \\
\hline $0-9$ & 7005 & 906 & 1.9 (1.8 to 2.1$)$ \\
\hline \multicolumn{4}{|l|}{ Men } \\
\hline 0 & 28 & 8 & $-0.3(-0.8$ to 0.1$)$ \\
\hline 1 & 137 & 48 & $0.1(-0.2$ to 0.4$)$ \\
\hline 2 & 381 & 79 & $0.5(0.1$ to 0.9$)$ \\
\hline 3 & 656 & 103 & 1.5 (1.1 to 1.9$)$ \\
\hline 4 & 608 & 93 & 2.0 (1.3 to 2.7$)$ \\
\hline 5 & 613 & 88 & 3.9 (2.6 to 4.9$)$ \\
\hline 6 & 363 & 26 & 7.1 (5.2 to 9.1 ) \\
\hline 7 & 156 & 15 & 8.6 (4.7 to 13.0 ) \\
\hline 8 & 21 & 3 & $15.9(7.0$ to 25.7$)$ \\
\hline $0-8$ & 2963 & 463 & $1.2(1.0$ to 1.4$)$ \\
\hline \multicolumn{4}{|c|}{ Women } \\
\hline 1 & 16 & 6 & $0.3(-0.4$ to 0.8$)$ \\
\hline 2 & 72 & 16 & $-0.1(-0.6$ to 0.3$)$ \\
\hline 3 & 357 & 62 & 1.5 (1.1 to 1.9$)$ \\
\hline 4 & 1065 & 144 & 2.4 (2.0 to 2.8$)$ \\
\hline 5 & 803 & 92 & 3.1 (2.3 to 3.8$)$ \\
\hline 6 & 997 & 78 & 8.0 (6.6 to 9.3$)$ \\
\hline 7 & 536 & 30 & 6.8 (4.4 to 9.1$)$ \\
\hline 8 & 164 & 15 & $12.4(7.9$ to 17.3$)$ \\
\hline 9 & 32 & 0 & 16.8 (3.1 to 30.5$)$ \\
\hline $1-9$ & 4042 & 443 & 2.7 (2.4 to 3.0$)$ \\
\hline
\end{tabular}

Danish $(-0.02(-0.15$ to 0.11$)){ }^{29}$ and Swedish (0.00 (not reported) $)^{30}$ cohorts.

\section{Direct oral anticoagulants}

A question that remains is whether the newer DOACs (dabigatran, rivaroxaban, apixaban and edoxaban) have a role in the treatment of lower-risk individuals. In DOAC trials (eg, randomized evaluation of long-term anticoagulant therapy (RE-LY), ${ }^{31}$ rivaroxaban once daily oral direct factor xa inhibition compared with vitamin $\mathrm{k}$ antagonism for prevention of stroke and embolism trial in atrial fibrillation (ROCKET-AF), ${ }^{32}$ apixaban for reduction in stroke and other thromboembolic events in atrial fibrillation (ARISTOTLE) ${ }^{33}$ and effective anticoagulation with factor xa next generation in atrial fibrillation-thrombolysis in myocardial Infarction 48 (ENGAGE AF-TIMI 48) ${ }^{34}$ ) all four agents were shown to be as effective in preventing ISs as warfarin, and associated with fewer HSs (see online supplementary table S9). We applied the trial reported relative risks of IS and HS to our data to consider the NCB of DOACs compared with no treatment. We found a significant positive NCB at
$\mathrm{CHA}_{2} \mathrm{DS}_{2}$-VASc $=1$ across all agents (see online supplementary table S10), and therefore some, although extrapolated evidence that DOACs may be a more suitable treatment option for those at lower stroke risk. We caution against interpreting this finding too strongly, however, as the extrapolated model takes on multiple assumptions. First, it assumes that the relative risk reduction is constant over the entire period of follow-up, and across all levels of the $\mathrm{CHA}_{2} \mathrm{DS}_{2}$-VASc score. Second, it assumes that the trial population is representative of the general AF population. And third, it assumes that the benefit and harm end point definitions are equivalent. All four DOAC trials were approximately 2 years in duration, which is comparable to the 2.2 median years of follow-up in this analysis. However based on trial eligibility criteria, patients at $\mathrm{CHA}_{2} \mathrm{DS}_{2}-\mathrm{VAS}_{\mathrm{C}}=1$ were largely excluded from DOAC trials, and as previously demonstrated these trials represented only a half to two-thirds of the AF population in the UK. ${ }^{35}$ Lastly, benefit and harm end point definitions did vary across trials (see online supplementary table S9).

\section{Clinical implications}

We confirmed that $\mathrm{CHA}_{2} \mathrm{DS}_{2}$-VASc is valid for estimating stroke risk in individuals with initial record of diagnosis in primary and secondary care, and therefore advocate use of the score across the full patient pathway. While we showed that lack of integration of primary and secondary care information may lead to inaccurate $\mathrm{CHA}_{2} \mathrm{DS}_{2}$-VASc scores, we do not regard this as an issue at point of care as clinicians are able to verify stroke risk factors with patients directly. However with the advent of clinical decision support systems, ${ }^{36}$ greater integration of primary and secondary care, and better recording of risk factors is urgently required in order to avoid undue patient harm through underestimation of stroke risk. Finally, we found insufficient evidence to support stroke prevention with warfarin at $\mathrm{CHA}_{2} \mathrm{DS}_{2}-\mathrm{VASc}=1$, and this may have relevance for future treatment guidelines. ${ }^{37}$

\section{Research implications}

Our findings highlight the value of linked EHRs in investigating individuals across the full pathway of primary and secondary care, and crucially in identifying individuals with $\mathrm{CHA}_{2} \mathrm{DS}_{2}$-VASc $=1$ in whom treatment guidelines have so far been unclear. Primary care records were instrumental in identifying individuals with $\mathrm{CHA}_{2} \mathrm{DS}_{2}-\mathrm{VASc}=1$ and we therefore propose wider utilisation of existing and discovery of new primary care data sources for studying these individuals in future research, and in particular in 'real-world' comparative effectiveness studies of DOACs. By comparison, several large-scale secondary care data sources have already been used in AF research, ${ }^{25} 28{ }^{38}$ however these are currently limited in terms of depth of clinical information, such as lack of prescriptions or biomarker data. We therefore propose wider linkage of routinely collected records to other clinical data sources such as disease-specific registries where deeper phenotype information is contained.

\section{Strengths and limitations}

Our study's principal strength was the inclusion of individuals, risk factors and end points captured across the full pathway of primary and secondary care, which is unlike previous studies that have predominantly focused on secondary care populations. We were limited by the depth and completeness of clinical information currently recorded in primary and secondary care records, however, we minimised the impact of this by analysing 
multiple data sources, and adopting robust phenotypes for capturing individuals, risk factors and end points. An example of the value of CALIBER phenotypes comes from hypertension. As shown, the proportion of individuals with baseline hypertension rose significantly when information from diagnosis codes was supplemented with blood pressure measurements and prescriptions data. It is however still possible that some individuals, risk factors and end points may have been overlooked, but we consider the number affected to be minimal, and less than previous studies. While the lack of DOAC data may be considered a limitation of the present analysis, it should be noted that warfarin remains the most widely used oral anticoagulant. Therefore, studies involving pre-DOAC era cohorts such as this are still shown to be of contemporary relevance. Lastly, though we included a large sample size of 70000 individuals, we found that only a quarter of the overall population had $\mathrm{CHA}_{2} \mathrm{DS}_{2}$-VASc scores 0,1 and 2 . We therefore cannot rule out the possibility that a positive $\mathrm{NCB}$ of warfarin may be observed at $\mathrm{CHA}_{2} \mathrm{DS}_{2}-\mathrm{VASc}=1$ given a larger study population.

\section{CONCLUSION}

$\mathrm{CHA}_{2} \mathrm{DS}_{2}$-VASc accurately stratifies IS risk in individuals with AF across both primary and secondary care. However IRs of IS at $\mathrm{CHA}_{2} \mathrm{DS}_{2}-\mathrm{VASc}=1$ are lower than previously reported, which may change the decision to start anticoagulation with warfarin in these individuals.

\section{Key messages}

\section{What is already known on this subject?}

It is unclear whether individuals with atrial fibrillation (AF) and $\mathrm{CHA}_{2} \mathrm{DS}_{2}-\mathrm{VASC}=1$ benefit from stroke prevention with warfarin. Previous large-scale, population-based studies have reported incidence of ischaemic stroke (IS) in individuals with $\mathrm{CHA}_{2} \mathrm{DS}_{2}-\mathrm{VASC}=1$; however have neglected the full patient pathway by focusing on those with initial record of diagnosis in secondary care.

\section{What might this study add?}

We confirmed that $\mathrm{CHA}_{2} \mathrm{DS}_{2}$-VASC accurately stratifies IS risk in individuals with $\mathrm{AF}$ across both primary and secondary care, however incidence rates (IRs) at $\mathrm{CHA}_{2} \mathrm{DS}_{2}-\mathrm{VASC}=1$ are lower than previously reported. We found a significant positive net clinical benefit of warfarin from $\mathrm{CHA}_{2} \mathrm{DS}_{2}-\mathrm{VASC} \geq 2$ in men and from $\mathrm{CHA}_{2} \mathrm{DS}_{2}-\mathrm{VASC} \geq 3$ in women, with $0.5(0.1$ to 0.9$)$ and 1.5 (1.1 to 1.9) ISs avoided per 100 person-years of warfarin treatment, respectively.

\section{How might this impact on clinical practice?}

IRs at $\mathrm{CHA}_{2} \mathrm{DS}_{2}-\mathrm{VASc}=1$ are lower than previously reported, which may change the decision to start anticoagulation with warfarin in these individuals.

\section{Twitter Follow Victoria Allan at @victoriaallanuk and Amitava Banerjee at} @amibanerjee1

Contributors VA analysed and interpreted the data, and drafted the manuscript. $\mathrm{HH}$ led the study as principal investigator. $A B$ contributed to interpretation of results and drafting of manuscript. ADS and RP contributed to the data analysis. SD extracted and validated the data. $A B, A D S, H H, J-P C, R P$ and $S D$ critically reviewed drafts of the manuscript, and approved the final version.
Funding This project was supported by the European Society of Cardiology, and the 10 funders of the Farr Institute of Health Informatics Research: The Medical Research Council (K006584/1) in partnership with Arthritis Research UK, the British Heart Foundation, Cancer Research UK, the Economic and Social Research Council, the Engineering and Physical Sciences Research Council, the NIHR, the National Institute for Social Care and Health Research (Welsh Assembly Government), the Chief Scientist Office (Scottish Government Health Directorates) and the Wellcome Trust.

\section{Competing interests None declared.}

Ethics approval CALIBER has received Ethics approval (ref: 09/H0810/16) and Ethics and Confidentiality Committee of the National Information Governance Board for Health and Social Care approval (ref: ECC 2-06(b)/2009 CALIBER data set).

Provenance and peer review Not commissioned; externally peer reviewed. Data sharing statement CALIBER data can be accessed on application.

Open Access This is an Open Access article distributed in accordance with the terms of the Creative Commons Attribution (CC BY 4.0) license, which permits others to distribute, remix, adapt and build upon this work, for commercial use, provided the original work is properly cited. See: http://creativecommons.org/licenses/ by/4.0/

\section{REFERENCES}

1 Lip GY, Nieuwlaat R, Pisters R, et al. Refining clinical risk stratification for predicting stroke and thromboembolism in atrial fibrillation using a novel risk factor-based approach: the euro heart survey on atrial fibrillation. Chest 2010;137:263-72.

2 Camm AJ, Lip GY, De Caterina R, et al. 2012 focused update of the ESC Guidelines for the management of atrial fibrillation: an update of the 2010 ESC Guidelines for the management of atrial fibrillation. Developed with the special contribution of the European Heart Rhythm Association. Eur Heart J 2012;33:2719-47.

3 National Institute for Health and Care Excellence. Atrial fibrillation: management. http://www.nice.org.uk/guidance/cg127 (accessed 13 Apr 2016).

4 January CT, Wann LS, Alpert JS, et al. 2014 AHA/ACC/HRS guideline for the management of patients with atrial fibrillation: a report of the American College of Cardiology/American Heart Association Task Force on Practice Guidelines and the Heart Rhythm Society. J Am Coll Cardiol 2014;64:e1-76.

5 Joundi RA, Cipriano LE, Sposato LA, et al. Ischemic stroke risk in patients with atrial fibrillation and CHA2DS2-VASC score of 1: systematic review and meta-analysis. Stroke 2016;47:1364-7.

6 Morley KI, Wallace J, Denaxas SC, et al. Defining disease phenotypes using national linked electronic health records: a case study of atrial fibrillation. PLOS ONE 2014;9: e110900.

7 Denaxas SC, George J, Herrett E, et al. Data resource profile: cardiovascular disease research using linked bespoke studies and electronic health records (CALIBER). Int J Epidemiol 2012;41:1625-38.

8 Forslund T, Wettermark B, Wandell P, et al. Risk scoring and thromboprophylactic treatment of patients with atrial fibrillation with and without access to primary healthcare data: experience from the Stockholm health care system. Int J Cardiol 2013;170:208-14.

9 Walley T, Mantgani A. The UK general practice research database. Lancet 1997;350:1097-9.

10 Health and Social Care Information Centre. Hospital Episodes Statistics (HES). http:/l www.hscic.gov.uk/hes (accessed 13 Apr 2016).

11 Herrett E, Smeeth L, Walker L, et al. The Myocardial Ischaemia National Audit Project (MINAP). Heart 2010;96:1264-7.

12 Office for National Statistics. Mortality Statistics: Deaths registered in England and Wales. http://www.ons.gov.uk/ons/rel/vsob1/mortality-statistics--deaths-registeredin-england-and-wales--series-dr-/index.html (accessed 13 Apr 2016).

13 Mathur R, Bhaskaran K, Chaturvedi N, et al. Completeness and usability of ethnicity data in UK-based primary care and hospital databases. J Public Health (Oxf) 2014;36:684-92

14 Herrett E, Gallagher AM, Bhaskaran K, et al. Data resource profile: Clinical Practice Research Datalink (CPRD). Int J Epidemiol 2015;44:827-36.

15 Chisholm J. The Read clinical classification. BMJ 1990;300:1092.

16 World Health Organisation. International Classification of Diseases (ICD). http:// www.who.int/classifications/icd/en/ (accessed 13 Apr 2016).

17 Rapsomaniki E, Timmis A, George J, et al. Blood pressure and incidence of twelve cardiovascular diseases: lifetime risks, healthy life-years lost, and age-specific associations in 1.25 million people. Lancet2014;383:1899-911.

18 Shah AD, Langenberg C, Rapsomaniki E, et al. Type 2 diabetes and incidence of cardiovascular diseases: a cohort study in 1.9 million people. Lancet Diabetes Endocrinol 2015;3:105-13.

19 Pujades-Rodriguez M, Timmis A, Stogiannis D, et al. Socioeconomic deprivation and the incidence of 12 cardiovascular diseases in 1.9 million women and men: implications for risk prediction and prevention. PLOS ONE 2014;9:e104671.

20 Pujades-Rodriguez M, George J, Shah AD, et al. Heterogeneous associations between smoking and a wide range of initial presentations of cardiovascular disease 
in 1937360 people in England: lifetime risks and implications for risk prediction. Int J Epidemiol 2015;44:129-41.

21 De Caterina R, Camm AJ. What is 'valvular' atrial fibrillation? A reappraisal. Eur Heart J 2014;35:3328-35.

22 National Institute for Health and Care Excellence. Hypertension in adults: diagnosis and management. http://www.nice.org.uk/guidance/cg127 (accessed 13 Apr 2016).

23 Gallagher AM, van Staa TP, Murray-Thomas T, et al. Population-based cohort study of warfarin-treated patients with atrial fibrillation: incidence of cardiovascular and bleeding outcomes. BMJ Open 2014;4:e003839.

24 Go AS, Mozaffarian D, Roger VL, et al. Heart disease and stroke statistics--2013 update: a report from the American Heart Association. Circulation 2013;127:e6-e245.

25 Friberg L, Skeppholm M, Terént A. Benefit of anticoagulation unlikely in patients with atrial fibrillation and a CHA2DS2-VASc score of 1. J Am Coll Cardiol 2015;65:225-32.

26 Herrett $E$, Shah $A D$, Boggon $R$, et al. Completeness and diagnostic validity of recording acute myocardial infarction events in primary care, hospital care, disease registry, and national mortality records: cohort study. BMJ 2013;346:f2350.

27 Singer DE, Chang Y, Fang MC, et al. The net clinical benefit of warfarin anticoagulation in atrial fibrillation. Ann Intern Med 2009;151:297-305.

28 Chao TF, Liu CJ, Wang KL, et al. Should atrial fibrillation patients with 1 additional risk factor of the CHA2DS2-VASc score (beyond sex) receive oral anticoagulation? J Am Coll Cardiol 2015;65:635-42.

29 Olesen JB, Lip GY, Lindhardsen J, et al. Risks of thromboembolism and bleeding with thromboprophylaxis in patients with atrial fibrillation: a net clinical benefit analysis using a 'real world' nationwide cohort study. Thromb Haemost 2011;106:739-49.
30 Friberg L, Rosenqvist M, Lip GY. Net clinical benefit of warfarin in patients with atrial fibrillation: a report from the Swedish atrial fibrillation cohort study. Circulation 2012;125:2298-307.

31 Connolly SJ, Ezekowitz MD, Yusuf $S$, et al. Dabigatran versus warfarin in patients with atrial fibrillation. N Engl J Med 2009;361:1139-51.

32 Patel MR, Mahaffey KW, Garg J, et al. Rivaroxaban versus warfarin in nonvalvular atrial fibrillation. N Engl J Med 2011;365:883-91.

33 Granger CB, Alexander JH, McMurray JJ, et al. Apixaban versus warfarin in patients with atrial fibrillation. N Engl J Med 2011;365:981-92.

34 Giugliano RP, Ruff CT, Braunwald E, et al. Edoxaban versus warfarin in patients with atrial fibrillation. N Engl J Med 2013;369:2093-104.

35 Lee S, Monz BU, Clemens A, et al. Representativeness of the dabigatran, apixaban and rivaroxaban clinical trial populations to real-world atrial fibrillation patients in the United Kingdom: a cross-sectional analysis using the General Practice Research Database. BMJ Open 2012;2:pii: e001768.

36 Chackery DG, Keshavjee K, Mirza K, et al. Integrating clinical decision support into EMR and PHR: a case study using anticoagulation. Stud Health Technol Inform 2015;208:98-103.

37 Kirchhof $P$, Benussi $S$, Kotecha $D$, et al. ESC guidelines for the management of atrial fibrillation developed in collaboration with EACTS. Eur H J (In press) 27 Aug 2016.

38 Olesen JB, Torp-Pedersen C, Hansen ML, et al. The value of the CHA2DS2-VASC score for refining stroke risk stratification in patients with atrial fibrillation with a CHADS2 score 0-1: a nationwide cohort study. Thromb Haemost 2012;107:1172-9. 